\title{
Relato de experiência no Canadá: conhecendo a inclusão escolar em Quebec
}

\author{
Mara Silvia Pasian* \\ Enicéia Gonçalves Mendes**
}

\section{Resumo}

O presente artigo relata uma visita de estudos ao Canadá, que foi parte das atividades científicas desenvolvidas ao longo do pós-doutorado da pesquisadora, na área de Educação Especial, apoiado pela FAPESP. O motivo principal desta visita foi conhecer aspectos relevantes da política de inclusão escolar de alunos com necessidades especiais em escolas públicas de ensino regular em uma cidade do interior de Quebec. Nesta visita, foi possível conhecer o espaço físico das escolas e das salas de aulas, além de outras observaçôes a respeito da infraestrutura das escolas e coletar informaçóes referentes ao funcionamento da sala de aula e dos alunos através de relatos do professor efetivo, do professor assistente e da psicóloga responsável. Como resultados, são apresentadas as principais características sobre a inclusão escolar em Quebec e os apoios fornecidos para as crianças com necessidades especiais no decorrer do ano letivo. Outro ponto relevante desta visita foi a possibilidade de conhecer qual o público atendido, como é realizada a identificação de alunos como especiais, como é a organização da sala de aula e quais são os profissionais envolvidos nos serviços de apoio. Espera-se socializar as informações coletadas com a comunidade científica brasileira interessada no tema, a fim de favorecer oportunidades de reflexôes e identificação de possíveis melhorias no atual modelo de inclusão escolar brasileiro.

Palavras-chave: Inclusão escolar; Educação especial; Intercâmbio educacional internacional.

\footnotetext{
* Pós-doutoranda em Educação Especial da Universidade Federal de São Carlos, São Carlos, São Paulo, Brasil.
}

** Professora doutora da Universidade Federal de São Carlos, São Carlos, São Paulo, Brasil. 


\section{Report of experience in Canada: knowing the scholar inclusion in Quebec}

\section{Abstract}

In this paper a scientific visit to Canada is reported, which was part of the scientific activities developed by the researcher during her post-doctoral project in Special Education supported by FAPESP. The main motivation of this visit was to obtain a deeper knowledge concerning important aspects on the scholar inclusion of students needing special cares in a city of the Province Quebec. During this visit, it was possible to learn about the physical aspects of schools and classrooms, to collect information about how these classrooms and the attended students from the reports of school teacher, teacher assistant and psychologist. As results, the main aspects of the school inclusion in Quebec are provided and also the activities developed for children with special needs throughout the school year. Moreover, the researcher could get knowledge on the attended as special care needed and how the diagnosis is performed and how is the organization of the classroom and professionals involved. The gains obtained from this experience have great impact for the researcher and will allow new perspectives and discussion on the Brazilian model of scholar inclusion.

Keywords: School inclusion; Special education; International educational exchange.

\section{Introdução}

O presente trabalho apresenta um relato de experiência que foi parte das atividades de um estágio de pós-doutorado em Educaçáo Especial da Universidade Federal de Sáo Carlos (UFSCar), apoiado pela FAPESP, cuja temática é a política de inclusão escolar dos estudantes público alvo da Educação Especial (PAEE) na sala comum e os serviços de apoio existentes nas escolas brasileiras. $\mathrm{O}$ enfoque da investigaçáo é a política de implantação do atendimento educacional especializado (AEE) nas salas de recursos multifuncionais (SRM).

No Brasil, o Ministério de Educação vem apoiando, desde 2005, a criação das SRM para o público-alvo da educação especial que frequenta o ensino regular. No contexto brasileiro, considera-se PAEE as pessoas com deficiência, com transtornos globais do desenvolvimento e com altas habilidades ou superdotação (BRASIL, 2011)

Assim, a implantação da SRM faz parte da ação do MEC, sendo um espaço para o AEE favorecer o desenvolvimento de competências e habilidades dos PAEE. O objetivo do AEE consiste em complementar ou suplementar através de procedimentos educacionais a aprendizagem com açóes distintas para cada tipo de aluno atendido, nas diferentes deficiências ou necessidades (ANJOS, 2011).

Tendo em vista a necessidade de acompanhar a implementação dessa política nacional de Educação Especial na perspectiva da educação inclusiva, foi constituído o Observatório Nacional de Educação Especial (Oneesp), que desenvolve estudos em 
rede nacional sobre políticas brasileiras de inclusão escolar. A atividade aqui relatada é baseada na experiência de uma visita de estudos visando conhecer a realidade de outro país, no caso o Canadá, considerado exemplar no tocante à política de inclusão de pessoas que possuem necessidades especiais. A experiência teve como foco conhecer essa realidade com o intuito de responder a questóes da política de inclusão escolar no contexto de um município (Quebec), enfocando como é feita a identificação dos alunos, como é a organização escolar para acolher esses alunos e como funcionam os serviços de apoio à escolarização nas classes comum. Deve-se considerar a limitação do estudo que representa a realidade de uma cidade de Quebec dentro de todo contexto do Canadá e também considerar que na realidade brasileira ocorrem diferenças entre as redes municipais e estaduais de diferentes regiôes.

\section{Ingresso no campo do município de Quebec}

O processo ocorreu durante o segundo semestre de 2013, após contato com o Prof. Dr. Carl Lacharité, da Universidade de Quebec em Trois-Rivières (UQTR), o qual encaminhou o pedido à psicóloga do serviço de inclusão escolar da cidade de Trois-Rivières. Essa profissional, Dra. Sylvie Desmet, providenciou para que fossem viabilizadas as visitas nas escolas, e se disponibilizou a fornecer informaçóes sobre os serviços oferecidos. Após o aceite de visita das instituiçóes pré-estabelecidas, se constituiu a oportunidade de intercâmbio entre o Brasil e o Canadá.

A experiência teve início com uma reunião na UQTR, com o professor doutor Carl Lacharité que forneceu informaçóes sobre o trabalho de seu grupo de pesquisa. O professor exerce a direção do Centro de Estudos Interdisciplinares sobre o desenvolvimento da criança e da família (CEIDEF), cuja missão é estabelecer relaçóes entre pesquisa, teoria e prática no campo do desenvolvimento da criança e da vida familiar. O CEIDEF tem como foco o estudo do desenvolvimento e a avaliação de programas de intervenção, visando o bem estar das famílias e das crianças para permitir a formação de uma plataforma interdisciplinar que pode atender às crescentes demandas de transmitir conhecimento sobre a criança e a família (LACHARITÉ, 2009, LACHARITÉ et al., 2005).

Posteriormente, foi realizada uma reunião com a psicóloga responsável pelo encaminhamento e acompanhamento das crianças público alvo da educação especial atendidas nas escolas comuns, que informou sobre como ocorre o processo de avaliação para identificação e o encaminhamento, e explicou o funcionamento geral desse serviço, além de viabilizar a visita para observar as salas de aula durante o período letivo.

\section{Caracterização da cidade}

Trois-Rivières é uma cidade localizada na província canadense de Quebec, localizada às margens do Rio São Lourenço. A sua área é de $145,65 \mathrm{~km}^{2}$, sua população é em torno de 134.012 habitantes, e sua densidade populacional é de $547,4 \mathrm{hab} / \mathrm{km}^{2}$. Além disso, há uma considerável quantidade de estudantes, população flutuante, que frequenta a "Université du Québec à Trois-Rivières", que aumenta o número de habitantes na cidade nos períodos de aula, compreendidos entre setembro e junho. 
Na região de Trois-Rivières, em torno de $10 \%$ da população apresenta alguma deficiência. As mais recorrentes são as relacionadas com problemas de mobilidade, deficiência intelectual ou de saúde mental e relativas à audição. Na cidade, há 29 escolas primárias e sete escolas secundárias.

A lei canadense exige que cada município com pelo menos 15.000 habitantes aprove anualmente um plano de ação com vistas a identificar as barreiras à integração de pessoas com deficiências, que contenha uma descrição das medidas previstas para o próximo ano, a fim de reduzir gradualmente estas barreiras. Este plano deve ser construído e publicado anualmente. $\mathrm{O}$ primeiro plano de ação municipal do conselho municipal de Trois-Rivières foi publicado em dezembro de 2005. A partir de entấo, os principais serviços municipais, desde 2006, estão sendo continuamente demandados a examinar as suas práticas e prestaçáo de serviços a fim de garantir os direitos aos cidadãos com deficiências. Em 2013, o município tinha dois desses planos em andamento, o Plano de Ação para Famílias e Pessoas com Deficiência e a Política de Integração das pessoas com Deficiências (TROIS-RIVIĖRES, 2013 a e b).

\section{Atividades realizadas nas escolas}

A pesquisadora realizou reunióes e visitas a três salas de aula regular em duas escolas de ensino primário onde havia a prática de inclusão escolar. Uma das escolas era localizada na periferia e atendia à regiấo rural, a outra escola era na regiáo central da cidade. $\mathrm{O}$ nome das escolas náo seráo divulgados para garantir o anonimato. Também foram coletadas informaçóes, através de entrevista, com uma profissional que trabalhava em uma escola secundária localizada na regiáo central da cidade.

As visitas visavam conhecer o espaço físico da escola e das salas de aulas, além de realizar observaçóes durante o curso letivo de um período. Também foram coletadas informaçóes referentes ao funcionamento da sala de aula e sobre os alunos com necessidades especiais que frequentavam as mesmas com o professor efetivo e o professor assistente.

A psicóloga da escola forneceu informaçóes sobre o trabalho desenvolvido com os alunos com deficiências que estavam sendo escolarizados nas classes comuns. Dessa forma, foi possível conhecer aspectos sobre a inclusão escolar das crianças com necessidades especiais e o desenvolvimento de atividades realizadas no decorrer do ano letivo, qual o público atendido, como era realizado o diagnóstico e como era a organização da sala de aula e os profissionais envolvidos.

\section{O público alvo da Educação Especial da inclusão escolar: as deficiências leves e de alta incidência}

Diferentemente da realidade brasileira, onde o PAEE é restrito a pessoas com deficiência, transtornos globais do desenvolvimento e com altas habilidades ou superdotação (BRASIL, 2008, 2011), em Quebec o público alvo é mais abrangente. Os estudantes considerados PAEE ou da política de inclusão escolar incluem crianças com dificuldades de aprendizagem, com hiperatividade com ou sem déficit de atençáo, com problemas de saúde (cardíacos, diabetes), autismo de grau leve, deficiência física, 
deficiência intelectual leve, com altas habilidades/superdotação e paralisia cerebral. O termo técnico adotado nos documentos é "handicap", e o conceito se aproxima de "necessidades educacionais especiais" (DECLARAÇÃO DE SALAMANCA,1994).

Assim, as crianças com deficiências que frequentam a escola comum são aquelas consideradas com limitaçôes leves, que a literatura tem apontado como deficiências de alta incidência, em referência ao fato de ser esta a população mais prevalente nas escolas comuns, e constituem cerca de $80 \%$ do público alvo da inclusão escolar. Elas incluem o grupo de crianças com distúrbios emocionais, dificuldades de aprendizagem, deficiência intelectual leve, autismo de auto-funcionamento, transtornos do déficit de atenção com e sem hiperatividade e dificuldades de fala e linguagem (GAGE, LIERHEIMER, GORAN, 2012).

Em contraposição ao grupo de alta-incidência, a literatura tem caracterizado o grupo de baixa incidência, em referencia a menor prevalência desses estudantes em escolas comuns, pois estes correspondem a $20 \%$ do público alvo das políticas de inclusão escolar. Friend e Bursuck (2012) caracterizam os estudantes com deficiência de baixa incidência como sendo aqueles que recebem serviços de educação especial desde o nascimento, incluem indivíduos com deficiência intelectual de moderada a severa e apresentam histórico de atraso desenvolvimental, deficiência visual, surdez, surdo-cegueira, paralisia cerebral e problemas ortopédicos com impedimentos motores mais severos, deficiências múltiplas e transtornos do espectro do autismo.

A distinção entre esses dois grupos tem sido feita em função dos tipos de suporte à inclusão escolar demandada, sendo que para o grupo de baixa incidência os suportes requeridos são mais variados e intensivos do que para os grupos de alta incidência. No caso da cidade visitada, para os alunos do grupo de alta incidência é fornecido suporte físico e profissional para que esses estudantes possam desenvolver as habilidades necessárias para acompanhar e participar do processo educativo, e não para garantir a mera presença dentro da classe comum.

\section{A inclusão de alunos com deficiência severa de baixa incidência}

Diferentemente da proposta de inclusão total apontada na literatura, e que parece ser hegemônica nas políticas de escolarização do público alvo das crianças com deficiência no Brasil (MENDES, 2006), no município canadense visitado as crianças com deficiências consideradas severas frequentam escolas especiais, que oferecem estrutura física adaptada e adequada às necessidades dos alunos, bem como profissionais preparados e serviços de diferentes profissionais envolvidos para favorecer o desenvolvimento dos alunos. Após o primário, que dura em média seis anos, a criança é inserida em uma escola secundária também especial, com duração de três anos. $\mathrm{O}$ material usado é adaptado à série de aprendizagem em que o aluno está, mas ele é inserido em turmas de crianças da mesma idade.

Após finalizar o primário e o secundário, com 16 anos, o aluno é encaminhado para fazer um curso profissional, onde irá estudar e trabalhar na forma de estágio. Esse estágio conta com supervisão de um chefe e é realizado com adaptaçóes ou 
acompanhamentos que possibilitem a realização do trabalho de forma produtiva. O que se espera com essas medidas é que o aluno tenha aprendizagem adequada durante sua formação, além de lograr ser inserido no mercado de trabalho e ser produtivo, trazendo ganhos para si e para a sociedade.

$\mathrm{Na}$ cidade visitada, há uma escola comum que recebe alunos com dificuldades de locomoção graves que precisam de cadeiras de rodas, sendo que esta conta com elevadores, carteiras e ambiente adaptado às suas necessidades. Tal escola pode ser enquadrada no conceito que surge no cenário das políticas de inclusão, e que ainda não está bem definido, de escola polo. Tais escolas são concebidas como aquelas que se especializam em práticas inclusivas destinadas a certos tipos de categorias de alunos, como, por exemplo, alunos surdos (LACERDA, ALBRES, DRAGO, 2013), ou para estudantes com deficiências visuais, autismo, deficiência intelectual mais grave, ou deficiências múltiplas.

Tais escolas são consideradas polo por concentrarem os recursos humanos e materiais necessários para dar suporte a determinados alunos, e assim permitir racionalizar os recursos e dar melhor suporte em função do aumento da competência da escola em atender as necessidades específicas do alunado. Por exemplo, uma escola polo para estudantes com paralisia cerebral permite centralizar os recursos de tecnologia assistiva e prover melhor formaçáo a todos os agentes educacionais, provendo melhores condiçóes para atender a esse tipo de alunado.

Contra a ideia de escolas polo se encontra o argumento de que as demais escolas não se preparariam para acolher bem a esse tipo de alunado, uma vez que haveria uma escola que se especializaria nisso. Além disso, seria preciso oferecer transporte, pois nem todos poderiam estudar nas escolas de seus bairros. Por outro lado, a favor da ideia de escolas polo há o argumento de que, na prática, tem se mostrado inviável adaptar a contento todas as escolas com os recursos materiais e humanos suficientes e adequados, quando a proposta é de provisóes descentralizadas. Assim, a consequência é que escassos recursos materiais e humanos são distribuídos entre as várias escolas, nem sempre de forma equitativa, resultando em escolas permanentemente despreparadas para acolher os alunos devido a escassez de recursos.

Particularmente no caso das deficiências de baixa incidência, que requerem mais variadas e intensivas provisóes, as escolas polo poderiam se constituir numa possibilidade importante a ser considerada no contexto brasileiro, tendo em vista a necessidade de melhorar a qualidade da escolarização em contextos inclusivos. As escolas polo poderiam ainda se constituir numa opção a mais às famílias dessas crianças que hoje são obrigadas a escolher entre duas opções igualmente insatisfatórias: uma escola pública despreparada para responder às necessidades de seus filhos e uma escola especial, privada e filantrópica, que também não consegue garantir uma educação de qualidade. 


\section{A identificação dos alunos do público alvo da Educação Especial}

A psicóloga das escolas forneceu informaçôes, em situação de entrevista informal, sobre algumas das diretrizes de como é realizado o processo de identificação e diagnóstico das crianças consideradas PAEE. A referida psicóloga trabalha com encaminhamentos de alunos de diversas escolas do município e é a responsável pela avaliaçáo inicial, ou triagem dos alunos, cujos professores suspeitam ter alguma deficiência, e em fazer o contato com os pais.

A professora da classe comum, quando constata algum problema, encaminha o aluno para ser avaliado. O mesmo ocorre no Brasil, sendo que vários estudos realizados com professores de SRM relatam o protagonismo do professor da sala comum no encaminhamento do aluno para a o AEE (MORAES et al., 2014; CASTRO; BASTOS; GONÇALVES, 2014; PASIAN; MENDES; CIA, 2013; TARTUCI et al., 2014). Pasian, Mendes e Cia coletaram informaçôes de 1202 professores de salas de recursos multifuncionais, 20 estados e mais de 100 municípios brasileiros, e constataram que mais de $70 \%$ dos respondentes afirmaram ser o professor de sala comum quem encaminha o aluno para o AEE.

Em Quebec, o encaminhamento inicial, realizado pela professora da sala comum, é seguido pela avaliação da psicóloga escolar responsável que inicia uma observação da criança em sala de aula e, se julgar necessário, realiza testes. Rigorosamente, antes de fazer qualquer teste ou avaliação, a família da criança é consultada e precisa fornecer autorização para o prosseguimento do processo de identificação e diagnóstico.

Após a avaliação, caso haja suspeita de alguma deficiência, a psicóloga encaminha para uma equipe multiprofissional que envolve profissionais da saúde, como fonoaudiólogo e fisioterapeuta. Os casos com suspeita de deficiência intelectual ou autismo são encaminhados para um médico neuro-psiquiatra, o qual deve fornecer um laudo com o diagnóstico final. Esse encaminhamento para a área de saúde é realizado após encontro da psicóloga escolar com os pais, onde os mesmos são informados sobre as suspeitas de deficiência e necessidade de avaliação adicional, sendo que estes tem que autorizar o encaminhamento para esses serviços.

A respeito da duração do processo de avaliação, a entrevistada respondeu que esse tempo é variável, em alguns casos sendo mais rápido, mas em outros podendo levar em torno de um ano. No Brasil, alguns casos, como nos casos de suspeita de autismo, os estudantes também são encaminhados para que médicos forneçam o laudo e, como ocorre em Quebec, o tempo para o retorno pode variar, sendo muitas vezes moroso. Alguns estudos realizados no Brasil revelam que o aluno é prejudicado pela demora do laudo médico e por vários percalços que ocorrem até sua obtenção, pois não pode ser atendido no serviço especializado (TARTUCI et al., 2014; MORAES et al. 2014). Entretanto, os professores de SRM relatam que alguns alunos frequentam o AEE mesmo sem a confirmação de serem do PAEE, enquanto esperam que a mesma seja providenciada (MORAES et al., 2014; TARTUCI et al., 2014). 


\section{Funcionamento/Organização das classes comuns inclusivas}

Os alunos em Quebec frequentavam as escolas durante o período de 8:00 as 15:30 horas, com intervalo para almoço, realizado na própria escola. No caso do aluno precisar ficar até o horário dos pais saírem do trabalho, é oferecido um serviço com atividades extras para os alunos. No Brasil, algumas medidas políticas estão sendo realizadas e algumas escolas oferecem a permanência de uma jornada maior para os alunos, que passam o dia na escola, mas em geral a jornada escolar é bem mais curta, em média cinco horas diárias.

A estrutura física da sala de aula conta com o espaço da professora, com um quadro interativo, diferente do quadro negro tradicional do Brasil. O quadro interativo é uma ferramenta que auxilia os professores a realizar a aprendizagem de forma mais motivadora, possui uma tecnologia para criação de instrumentos de aprendizagem, é controlado pelo computador e é sensível ao toque. Em sala de aula, o professor e o aluno podem usar imagens, sons, textos, fazer cálculos, fazer apresentaçôes e utilizar a Internet. A sala também conta com uma mesa grande e outra pequena, onde fica o computador. A distribuição das carteiras é a mesma encontrada no Brasil, em fileiras e com espaço entre as mesmas. No fundo da sala há um espaço com cinco computadores e uma pequena biblioteca, que conta com livros e o jornal do dia.

A distribuição do espaço físico é bem agradável e proporciona boa mobilidade para os alunos e professores transitarem. O suporte que há no fundo da sala (computadores e biblioteca) é usado em diversos momentos, por exemplo, quando o professor passa uma atividade para os alunos fazerem, e aqueles que a finalizam váo até o espaço de atividades e optam pelo computador ou biblioteca. Dessa forma, todos estáo engajados em alguma atividade enquanto esperam os colegas da sala terminarem a mesma e o professor pode dar atenção aos que precisam de auxílio adicional.

Essa distribuição de espaço e atividades paralelas é muito interessante e difere da realidade brasileira, onde os alunos que acabam primeiro as atividades esperam a finalização do trabalho dos colegas sem realizar qualquer outra atividade. A conduta dos alunos é tranquila ao se dirigir para o fundo da sala e escolher a atividade a realizar e isso parece agradar os alunos.

Quando todos os alunos terminam o exercício proposto, a professora avisa e o retorno às carteiras é realizado rapidamente, pois essa prática se tornou rotina. $\mathrm{O}$ custo de investimento não é alto e o retorno pode ser produtivo, pois o aluno faz alguma atividade enquanto espera os colegas, afinal esperar sem "nada a fazer" pode incentivar a conversa e atitudes de indisciplina, que é uma grande reclamação entre as escolas e os professores na realidade brasileira. $\mathrm{O}$ custo pode ser revertido em melhora no comportamento dos alunos e no serviço do professor em atençáo aos alunos que precisam de mais tempo para as atividades, retornando como melhoria no rendimento escolar.

As salas de aulas têm, no máximo, 25 alunos cada. Quando há aluno com alguma necessidade especial, o mesmo conta por dois alunos e esse número é subtraído do total de alunos por turma. Por exemplo, se o professor tiver dois alunos com 
deficiência, o número máximo de sua turma será de 21 alunos por sala de aula. Isso contribui para que o professor possa dar atenção adequada a todos os alunos e serve de incentivo para que os professores acolham estudantes com deficiências em sua turma. Tal prática é diferente da realidade brasileira, na qual, muitas vezes, as salas de aulas atendem em torno de 35 a 40 alunos por turma, incluindo os alunos PAEE. O professor da sala de aula trabalha em torno de 30 horas por semana, e em todos os meses um dia é destinado ao planejamento, no qual as aulas são suspensas para os alunos.

As salas de aulas com alunos com necessidades especiais possuem um professor assistente, que fica o tempo todo junto aos alunos, tanto na classe comum quanto em outras aulas ou atividades, como educação física e artes. Tal provisão auxilia na realização do trabalho acadêmico, pois o professor assistente fornece um suporte aos alunos da turma que enfrentam dificuldades em melhorar seu rendimento acadêmico.

O currículo acadêmico dos alunos com necessidades especiais é o mesmo dos outros alunos, podendo haver adaptações quando necessário. $\mathrm{O}$ aluno acompanha a série pela idade cronológica, mesmo que não tenha obtido a aprendizagem requerida da série anterior. Nesse caso, o aluno frequenta a série de acordo com sua idade, mas utiliza o material pedagógico da série anterior, na(s) disciplina(s) em que não adquiriu o conhecimento/rendimento necessário. Por exemplo, na aula de matemática, o professor assistente pode trabalhar com esse aluno dentro da sala comum, mas utilizando o livro de matemática da série anterior.

Nas salas de aula de terceiro ano, havia dois alunos com autismo leve, uma aluna com dificuldades de aprendizagem e outra com diabetes. $\mathrm{Na}$ sala de segundo ano observada, havia um aluno com deficiência intelectual, um com dificuldade de aprendizagem, um com déficit de atenção e um com autismo de grau leve. O professor assistente proporcionava algumas atividades de incentivo para esses alunos, por exemplo: a utilização de uma tabela de pontuação diária e semanal para o comportamento e rendimento do aluno. Como material, o professor utilizava uma folha onde assinalava uma estrela a cada atividade realizada de forma adequada. Caso o aluno recebesse cinco estrelas no final do período letivo, ganhava um brinde, que normalmente era fazer alguma atividade que gostasse nos últimos 15 minutos da jornada diária, que poderia ser utilizado no computador ou para ir à biblioteca, atividades que os alunos pareciam gostar muito. No final da semana essa folha era encaminhada aos pais e deveria retornar assinada, assim eles poderiam acompanhar o histórico de atividades da criança.

Enfim, algumas diferenças na organização escolar que se percebe, entre as classes inclusivas no Brasil e no contexto visitado, é que os estudantes canadenses têm pelo menos três horas a mais por dia de permanência na escola, o que significa que têm mais oportunidades de aprender. As salas de aula têm mais recursos materiais, e para alunos com deficiências esses recursos se encontram centrados na própria classe comum, e não em classes separadas, como é o caso das salas de recursos brasileiras. 
Assim, a inclusão implica em levar não apenas os alunos, mas também os recursos que eles precisam para as classes comuns. Um recurso valioso no sistema observado é a presença de um professor de apoio atuando em sala junto ao professor regente quando há alunos com deficiências nas turmas. Mendes, Vilaronga e Zerbato (2014) mostraram evidências na realidade brasileira de ser promissora a presença de professores especializados na classe comum para fornecer apoio. Além disso, cabe destacar a importância do tempo destinado ao planejamento, da jornada de trabalho da professora que pode se dedicar a uma única escola, as estratégias para manter acesso ao currículo, e, como no conjunto, essas provisóes contribuem para qualificar o ensino oferecido na classe comum, o que reduz a necessidade de complementaçáo ou suplementação.

\section{Considerações finais}

A visita de estudos realizada permitiu conhecer escolas de ensino comum em uma cidade do interior de Quebec que atendia alunos com necessidades especiais, no tocante ao espaço físico das escolas e das salas de aulas. Também permitiu coletar informaçóes referentes ao funcionamento da sala de aula e dos alunos, tanto com o professor regente quanto com o assistente, além de entrevistar a psicóloga responsável pelo processo de identificação dos alunos do público alvo da Educação Especial. Dessa forma, pode-se conhecer na prática a política de inclusão escolar em curso no contexto do município.

Conhecer a realidade de outro país, principalmente considerado de referência em educação e inclusão escolar, é importante para coletar informaçóes e conhecer como outros países enfrentam esse desafio. Tal conhecimento pode colaborar para se analisar as semelhanças e diferenças entre os dois países, assim como contribuir para que novas ideias possam ser testadas e avaliadas para melhorar as políticas e práticas de inclusão escolar do PAEE no Brasil.

Pode-se observar que, apesar de uma proposta explícita de política de inclusão escolar, os alunos com deficiências severas ainda continuam sendo atendidos em salas e escolas especiais, com acompanhamento de vários profissionais e com apoio até sua formação e estágio profissional. Isso leva a refletir se a política de inclusão total é de fato viável. É possível pregar que todos os alunos PAEE devam ser escolarizados em classes comuns? Será que uma formação que os encaminhe a serem produtivos e ter inserção social futura é uma realização do próprio ser ou uma necessidade da sociedade?

Enfim, é preciso pensar, investigar e realmente oferecer alternativas para que o aluno PAEE desenvolva melhor seu potencial, e oferecer alternativas que o auxilie a alcançar melhores resultados para toda vida. Nesse sentido, uma lição a ser seguida é de que os pais devem participar e ter o poder de optar qual o melhor tipo de escolarização para seus filhos com deficiência.

Os alunos considerados com necessidades especiais em Quebec abrangem um universo bem maior do PAEE da realidade brasileira, pois inclui crianças com dificuldades de aprendizagem, crianças com hiperatividade, com déficit de atenção, com 
problemas de saúde como cardíacos, diabetes, autismo, deficiência física, deficiência mental, com altas habilidades/superdotação e com paralisia cerebral. No Brasil, o PAEE é bem mais restrito, e se de um lado isso pode ser considerado positivo, pois as verbas da Educação Especial podem ser destinadas a um público menor, por outro lado, como ficam as crianças que possuem problemas para acompanhar o ensino da sala de aula e não estão inseridas dentro do PAEE? Por outro lado, com uma escola de baixa qualidade como a brasileira, a adoção de uma concepção mais ampliada de público alvo, englobando todos os alunos que não tem sucesso na escola, iria implicar num crescimento enorme na populaçáo alvo, sem nenhuma garantia de que os recursos adicionais iriam aumentar da mesma proporção. Assim, a probabilidade de diluição dos escassos recursos seria grande, o que deixaria possivelmente mais desassistida a população de crianças com deficiências mais severas.

Assim, o conceito restrito de PAEE favorece a diminuição do público atendido, o que não significa que a escola não possa ter outros tipos de apoios às outras crianças, para que elas não sejam marginalizadas pelo sistema. Entretanto, cabe destacar que a adoção de um conceito restrito de PAEE não tem impedido que muitas crianças com dificuldades escolares de todo tipo sejam identificadas como sendo do PAEE para que estas possam usufruir do AEE ou eximir a escola de ensiná-las (MORAES et al, 2014.; TARTUCI et al., 2014).

O Canadá possui um serviço de referência de qualidade em política de inclusão escolar e fornece um investimento alto em educação. Algumas comparações entre semelhanças e diferenças na realidade Brasil/Canadá foram mostradas e discutidas e algumas questóes, advindas dessa experiência, foram levantadas para serem pensadas. Relembrando que o estudo tem sua limitação por representar uma parte da realidade canadense, sendo realizado em uma única cidade de Quebec.

O Brasil encontra-se entre os países que apresentam pior índice na qualidade de educação (BONAMINO; COSCARELLI; FRANCO; 2006; PASIAN; VELTRONE; CAETANO; 2012; PASIAN; ROSE, 2011). De acordo com dados do Instituto Nacional de Estudos e Pesquisas Educacionais mais de 40\% dos alunos que ingressam na $1^{\text {a }}$ série do Ensino Fundamental não consegue terminar a $8^{\mathrm{a}}$ série (BONAMINO; COSCARELLI; FRANCO, 2006; PASIAN; ROSE, 2011). Evidencia-se a necessidade de investimento na educação brasileira para todos os alunos, incluindo o PAEE.

Outro fator importante a destacar é a necessidade de valorizaçấo dos professores brasileiros, com salários dignos e investimento em sua formação inicial e continuada. Muitas vezes os professores fazem mais de uma jornada de trabalho pela necessidade de complementarem seu orçamento, além do desgaste físico, não contam com tempo para aprimorar e atualizar seu conhecimento, o que é fundamental para melhorar a capacitação dos mesmos e, assim, a qualidade do ensino.

Em suma, se temos algo a aprender com essa experiência no Canadá é que a inclusão escolar é uma questão de como melhorar a escola e o ensino na classe comum para todos os alunos. Náo apenas de se prover atendimento diferenciado extraclasse para determinados tipos de alunos, enquanto a escola, que oferece ensino de baixa qualidade para todos, permanece inalterada. 


\section{Referências}

ANJOS, I. R. S. O atendimento educacional especializado em salas de recursos Itabaiana: Gepiadde, 5, v. 9, 2011

BRASIL. Decreto n. 7611 de 17 de novembro de 2011. Dispóe sobre a educação especial, o atendimento educacional especializado e dá outras providências. Presidência da República/Casa Civil/Subchefia para Assuntos Jurídicos. Brasília, 2011.

Decreto no 6.571, de 17 de setembro de 2008. Dispóe sobre o atendimento educacional especializado. Presidência da República/Casa Civil/Subchefia para Assuntos Jurídicos. Brasília. 2008.

BONAMINO, A.; COSCARELLI, C.; FRANCO, C. A. Avaliação e Letramento: Concepçóes de Aluno Letrado Subjacentes ao SAEB E AO PISA. Educaçáo e Sociedade, v. 23 n. 81, p. 91-113, 2006.

CASTRO, A. S. A.; BASTOS, E. R. O.; GONÇALVES, I. M. C. Problematizando a avaliação de estudantes com necessidades educacionais em salas de recursos multifuncionais em FEIRA de SANTANA. In: Encontro do Observatório Nacional de Educação Especial, IV, São Paulo. Anais do IV EONEESP, 2014.

DECLARAÇÃO DE SALAMANCA: Sobre Princípios, Políticas e Práticas na Área das Necessidades Educativas Especiais. Salamanca-Espanha, 1994.

FRIEND, M.; BURSUCK,W. D. Including students with special needs: a practical guide for classroom teachers. 7 Ed. 2012. New Jersey: Pearson Education Inc, 2012.

GAGE, N. A.; LIERHEIMER,K. S.; GORAN, L. G. Characteristics of students with high-incidence disabilities broadly defined. Journal of disability policy studies. Dez., p. 168-178, 2012 .

LACERDA, C. B. F.; ALBRES, N. A.; DRAGO, S. L. S. Política para uma educaçáo bilíngue e inclusiva a alunos surdos no município de São Paulo. Educ. Pesqui., v. 39, n.1, 2013,

LACHARITE, C. Approche participative auprès des familles. Dans Lacharité, C., Gagnier, J.P. (sous la direction de), Comprendre les familles pour mieux intervenir : repères conceptuels et logiques d'action. Montréal: Chenelière. 112-131, 2009.

LACHARITE, C.; DEMONTIGNY, F.; MIRON, J. M. et al. Le soutien professionnel aux parents à risque ou en difficulté : modèles conceptuels, stratégies d'action et réponses aux besoins. Trois-Rivières: Groupe de recherche en développement de l'enfant, 2005.

MENDES, E. G.; VILARONGA, C. A. R.; ZERBATO, A. P. Ensino Colaborativo como apoio à Inclusáo Escolar. 1. ed. São Carlos: EDUFSCar, 2014. v. 1. 160p

MENDES, E. G. A radicalização do debate sobre inclusão escolar no Brasil. Revista Brasileira de Educaçáo, Campinas, v. 11, p. 387-405, 2006.

MORAES, W. D. F.; et al. Aspectos da avaliação na política de implantação de salas de recursos multifuncionais na rede pública de Maceió/Al. In: Encontro do Observatório Nacional de Educaçáo Especial, IV, São Paulo. Anais do IV EONEESP, 2014.

PASIAN, M. S.; ROSE, T. M. S. Tutoria centrada na leitura de livros: uma alterantiva para alunos com dificuldades em leitura e escrita. Estudos em avaliaçáo educacional, v. 22, n. 50, p. 577-592, 2011.

PASIAN, M. S.; VELTRONE, A; CAETANO, N. Avaliaçôes educacionais e seus resultados: revelando ou omitindo a realidade brasileira sobre o fracasso escolar. Revista Eletrônica de Educaçáo, UFSCar, 2012.

PASIAN, M. S.; MENDES, E.G.; CIA, F. O funcionamento pedagógico nas salas de recursos multifuncionais: revisão de trabalhos em eventos científicos. Cadernos da FUCAMP, v. 12, p. 17-27, 2013.

TARTUCI, D; et al. Avaliação nas salas de recursos multifuncionais no contexto da educação inclusiva em goiás. In: Encontro do Observatório Nacional de Educação Especial, IV, 2014, São Paulo. Anais do IV EONEESP, 2014.

TROIS-RIVIÈRES. Plan_d'action_famille et personne_handicapée_2013. 2013a. Disponivel em: <http:// laville.v3r.net/docs_upload/documents/langue1/pol_mun_famille/Plan_d_action_famille_personne_handicapee_2013.pdf>. Acesso em: 23 abr. 2015.

Politique-Intégration_des_personnes_handicapées. 2013b. Disponivel em: <http://laville.v3r.net/ docs_upload/documents/langue1/pol_mun_handi/Politique-Integration_des_personnes_handicapees.pdf>. Acesso em: 23 abr. 2015. 


\section{Correspondência}

Mara Silvia Pasian - Universidade Federal de São Carlos, Centro de Educaçăo e Ciências Humanas. Rodovia Washington Luís, km 235 - SP-310, CEP:13565-905 - São Carlos, São Paulo - Brasil.

E-mail:marasilvia123@yahoo.com.br - egmendes@ufscar.com

Recebido em 30 de abril de 2015

Aprovado em 09 de outubro de 2015 